\title{
Optimising oral health in frail older people
}

\section{SUMMARY}

There is a link between oral health and systemic health. Conditions such as dementia and pneumonia are associated with poor oral health.

Frail older people receive regular care from medical and nursing staff but tend not to see dentists regularly or only seek treatment when there is a dental problem. Collaboration between dentists and other health professionals is therefore increasingly important.

Oral health should be assessed regularly. This enables early referral to a dentist.

Anticholinergic drugs, particularly in polypharmacy, can have a profound deleterious effect on salivary function and oral health. A medication review may enable the anticholinergic burden to be reduced.

In addition to regular brushing, oral preventive products may be appropriate in frail older people.

\section{Introduction}

Most oral and dental problems in frail older people may not be obvious to relatives and health professionals. Older people do not see dentists regularly but receive regular care from medical and nursing professionals, so collaboration with dentists is important. This is especially the case in residential aged care. Improved oral health outcomes are achievable using an interdisciplinary approach involving GPs, dentists, oral health therapists, dental prosthetists and nurses trained in oral health.

\section{Relationship between oral and systemic health}

There is a link between poor oral health and systemic disease. There are correlations between adequate mastication and activities of daily living, nutritional status and quality of life.

A significant association exists between the severity of periodontal disease, increasing tooth loss and carotid artery plaque.' This may increase all-cause mortality in cardiovascular disease including ischaemic stroke. ${ }^{2}$

Chewing increases regional neural activity and cerebral blood flow. ${ }^{3,4}$ The number of teeth lost may be a predictor of cognitive decline and dementia. ${ }^{5-7}$ The bacteria that cause periodontal disease have been implicated in Alzheimer's disease. ${ }^{8}$

There is an association between oral health and respiratory disease. ${ }^{9}$ Randomised controlled trials show that improved oral hygiene reduces the progression or occurrence of respiratory diseases and death from pneumonia among high-risk older adults living in residential care. ${ }^{10}$
Diabetes increases the risk for periodontitis. Periodontal inflammation negatively affects glycaemic control causing systemic complications. Severe periodontitis increases the risk of cardiorenal mortality 3.2 times. Periodontal treatment and better oral hygiene can improve metabolic control."

\section{The importance of saliva}

Normal salivary function is essential in speech, digestion and swallowing. Saliva has antimicrobial activity and prevents decay and tooth wear. In healthy people, stimulated saliva has a high serous volume with higher bicarbonate buffering concentrations to neutralise mouth, food and plaque acids compared to resting saliva. High flow volumes are essential for effective buffering capacity, clearance of glucose and bacteria, and swallowing.

In frail older people with decreased salivary function and poor oral hygiene, teeth may rapidly demineralise when not in a supersaturated solution of calcium and phosphate ions provided by saliva. Teeth will also decay more rapidly as mouth $\mathrm{pH}$ is unable to return to safe values due to a lack of buffering capacity, particularly if there is frequent snacking on sweet foods and drinks.

\section{Salivary gland hypofunction and dry mouth}

GPs should be encouraged to ask patients about a dry mouth. The prevalence of salivary gland hypofunction (measurable decrease in salivary flow) and xerostomia (subjective feeling of dry mouth) increases with age, the number of chronic conditions and is strongly associated with drugs. The prevalence of xerostomia can be over $50 \%$ for people taking more than five drugs and it has marked effects on oral health and quality of life.

\section{Alan Deutsch \\ Principal' \\ Geriatric Dental Advisory Group Member ${ }^{2}$ \\ Emma Jay \\ Clinical lecturer ${ }^{3}$ \\ Geriatric Dental Advisory Group Member ${ }^{2}$ \\ 'Bondi Junction Dental Centre \\ ${ }^{2}$ Centre for Education and Research on Ageing, Concord Repatriation General Hospital \\ ${ }^{3}$ Faculty of Medicine and Health, University of Sydney Sydney}

\section{Keywords}

aged, anticholinergic drugs, oral health, oral hygiene, saliva

Aust Prescr 2021;44:153-60 https://doi.org/10.18773/ austprescr.2021.037 
Hyposalivation can significantly impact activities of daily living such as speaking, eating and sleeping. It may cause tingling, a decreased sense of taste, halitosis and difficulty in wearing dentures. It can increase the risk of opportunistic infections such as Candida albicans. Low saliva flow rates correspond to lower mucosal wetness and increase pathogenic aciduric microorganisms in the oropharynx, mouth and dental plaque (which can be inhaled).

\section{Tooth decay in older people}

Tooth decay is manageable if treated promptly so early referral is important. Root surface decay is common in older people (Figs 1 and 2). It is more

\section{Fig. 1 Root caries}

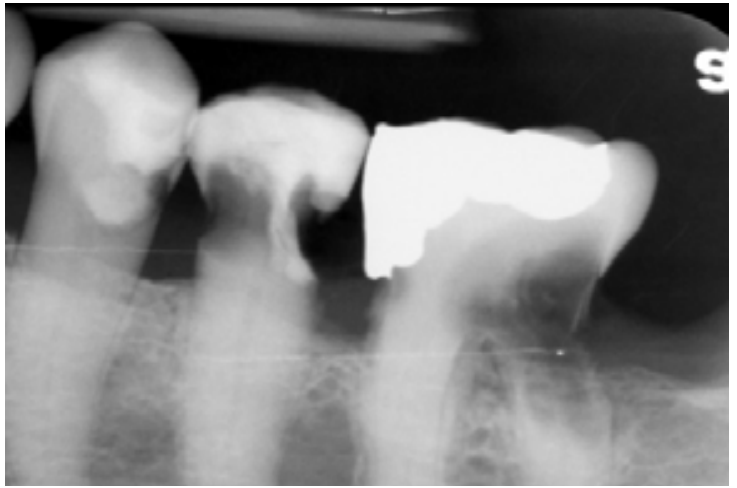

Advanced root caries involving the nerve and extending under the gumline. Crowns will snap off to leave root stumps. Visual examination alone may not be able to detect decay under the gumline and in the back of the mouth.

\section{Fig. 2 Tooth decay}

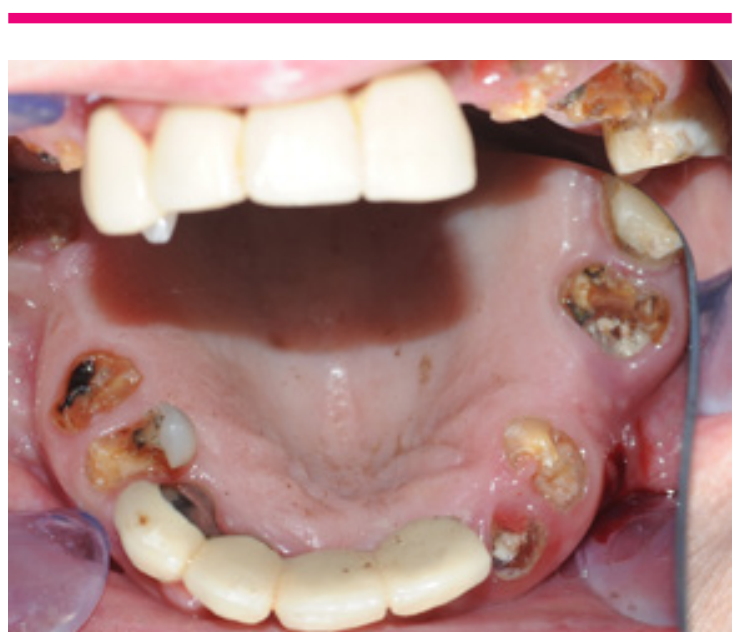

Decaying teeth in a relatively clean mouth of a person with dementia. Salivary gland hypofunction may be involved in the progression of decay. difficult to detect than decay affecting the crowns of the teeth (coronal caries) and progresses much more rapidly. In 10 Sydney residential aged-care facilities, $46 \%$ of residents (mean age 86.9 years) had 1-3 decayed teeth and $7 \%$ had more than four decayed teeth on entry. ${ }^{12}$ In another study of 19 facilities in Melbourne, $68 \%$ of residents had coronal caries (mean 2.6) and 77\% had root caries (mean 5).13

Tooth loss has further effects on nutrition, systemic health, quality of life and the ability to socialise. Every effort should be made to prevent decay progressing to the pulp (nerve) of the tooth. Exposed nerves and root stumps, even when symptom free, act as wicks for oral bacteria to infect bone. This can cause multiple chronic dental abscesses adding to the inflammatory burden of the patient. Treatment may require hospitalisation to remove teeth due to recurring dental infections, when there is a lack of co-operation as in dementia or delirium, or when the airway and swallowing may become compromised during dental procedures (Fig. 3).

Silver fluorides are potent biocides that can prevent and stop caries. ${ }^{14}$ They also improve gingival health when applied topically to susceptible teeth every 3-6 months. Drilling is often not required so applications are non-threatening and ideal for frail or fearful patients showing challenging behaviours.

Symptom-free chronic infections in bone, arising from infected nerves or from periodontitis, are common findings on dental radiographs but may not be obvious on a visual examination. If untreated these infections can complicate medical conditions and future management.

\section{Fig. 3 Infected root stumps}

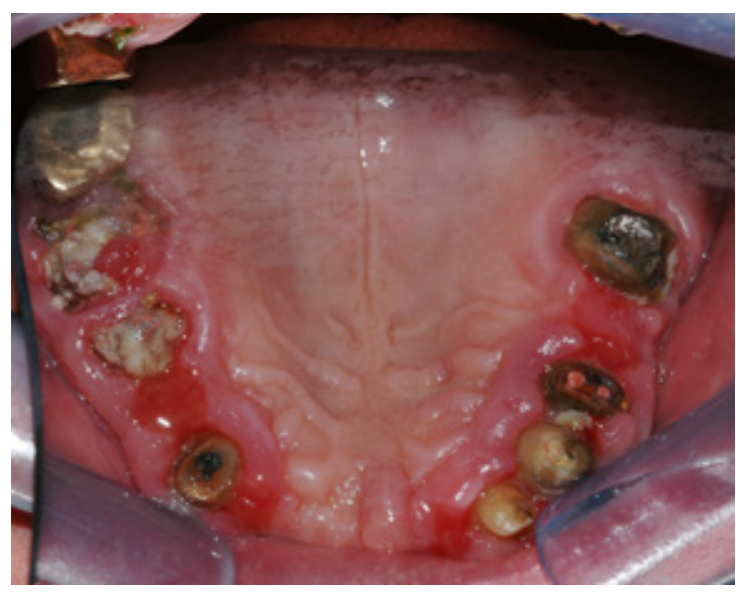

Multiple roots stumps with infections in the bone in a patient with dementia. This is a common finding and removing all teeth will require a general anaesthetic. 


\section{Drugs can affect oral health}

A significant association exists between prescription medicines, saliva function and rapidly progressing multiple decaying teeth. ${ }^{15}$ Many drugs prescribed for older patients have anticholinergic activity. These may cause a marked decrease in saliva flow as they prevent parasympathetic (cholinergic) activity at the muscarinic receptors in salivary glands. ${ }^{16}$

Polypharmacy is common in older people. ${ }^{17}$ Different classes of drugs have different levels of anticholinergic activity and can add to the overall anticholinergic burden. In general, medicines for urinary incontinence, antidepressants and antipsychotics have the greatest effects and are significantly associated with xerostomia and salivary gland hypofunction. ${ }^{18-21}$ In complex cases a medication review with a pharmacist may be appropriate. The anticholinergic burden may be minimised by considering the following:

- Order a medication review and deprescribe when possible. ${ }^{22}$

- Switch to a drug with less anticholinergic activity. ${ }^{19-21}$

- Reduce the dose as anticholinergic effects are dose related.

- Administer drugs during the day rather than at night. Resting saliva is lowest at night and higher during the day.

- $\quad$ Divide the dose into smaller doses throughout the day.

- Check for adverse drug interactions that cause increased drug concentrations due to inhibition of drug metabolism or clearance.

\section{Commonly used drugs with adverse oral effects}

Oral adverse drug reactions are common, varying in nature and severity. ${ }^{23}$

The corticosteroid inhalers used in asthma and chronic obstructive pulmonary disease can cause pharyngitis, oral mucositis (ulcerations) and candidiasis particularly in the elderly. The inhalers used to relieve acute asthma, such as salbutamol and terbutaline, are beta ${ }_{2}$ agonists. They reduce saliva flow and lower its $\mathrm{pH}$ causing increased decay rates and tooth wear. Additional adverse reactions are taste alterations, gingivitis and gingival enlargement. ${ }^{24}$ Patients should be instructed to rinse and gargle with water after using their inhalers. They should also use a daily fluoride rinse.

Bruxism and dyskinesia are associated with the selective serotonin reuptake inhibitors and antipsychotic drugs. Metoclopramide may be associated with tardive dyskinesia which may persist and be irreversible, especially in older people. Uncontrolled movements of the tongue and lips make denture wearing exceedingly difficult. ${ }^{23}$

Calcium channel blockers, valproate, phenytoin and cyclosporin can cause gingival enlargement. Anticoagulants can cause bleeding from the gums.

Drugs associated with lichenoid sensitivity reactions are non-steroidal anti-inflammatory drugs and antihypertensives, including beta blockers, ACE inhibitors and diuretics. ${ }^{24}$ Cutaneous lichenoid hypersensitivity reactions may resemble oral lichen planus.

Rarely, antiresorptive drugs such as bisphosphonates and denosumab can cause osteonecrosis of the jaw. This can be spontaneous from denture trauma, or occur after extractions due to poor bone healing.

It is advisable for GPs to refer patients for dental examinations with dental radiographs before starting bisphosphonates or denosumab, before cardiac or major surgery, and before head and neck radiotherapy. Radiotherapy adversely affects bone healing at extraction sites and markedly decreases saliva function resulting in increased decay rates.

Chemotherapy drugs, such as 5-fluorouracil, cisplatin, methotrexate, and hydroxyurea can cause painful oral ulcers and ulcerative mucositis. ${ }^{24}$

\section{Patient assessment and referral}

GPs and residential aged-care nurses should be encouraged to look into patients' mouths to assess oral health. Use a strong light (preferably a headlight) with gauze to wipe teeth and gums, and two dental mirrors. One mirror is used to retract lips and tongue and the other to visualise soft tissues and teeth. These aids greatly assist screening for decaying teeth, ulcers, dental infections and oral cancers. Most oral ulcerations either heal themselves or resolve after simple dental intervention within 2-3 weeks. Any area that persists longer than three weeks may be suspicious.

There is an Oral Health Assessment Tool that can be used by GPs, residential aged-care nurses and allied health professionals, but requires some training to use. It is a validated tool to detect early oral problems and provides guidance on when to refer to a dentist. There are eight categories to assess - lips, tongue, gums and tissues, saliva, natural teeth, dentures, oral cleanliness and pain. They are scored as healthy, changes, unhealthy or needing referral.

Referrals by GPs to dentists should be routine and ideally part of over 75 years of age health assessments or chronic disease management plans. It is often difficult for dentists to obtain a full medical history and medicines list from older patients. Dentists may need to phone GPs to ask about 
comorbidities and the patients' medicines, particularly anticoagulant drugs.

Dental referral is also encouraged before receiving a residential or home-care package. The better someone's oral health is before entering a facility, the better their long-term systemic and oral health outcomes will be.

\section{Risk indicators and risk stratification}

Patients are evaluated for the risk of:

- oral infections and pain from decaying teeth, root stumps, periodontitis

- aspiration pneumonia from salivary gland hypofunction together with poor swallowing ability and poor oral hygiene

- adequate nutrition from poor chewing ability and denture stability, pain

- $\quad$ psychosocial problems and depression related to poor anterior aesthetics, poor chewing ability or pain.
Assessing a person's degree of risk can help to guide patient management and referral to a dentist (Box 1). Useful oral health screening questions for older people able to self-report are: ${ }^{25}$

- Have you had pain in your mouth while chewing?

- Have you lost any fillings, or do you need a dental visit for any other reason?

- Have you avoided laughing or smiling?

- Have you had to interrupt meals due to dental pain, unstable dentures that hurt, difficulty swallowing, mouth being too dry, inappropriate diet or embarrassment?

Older people who may not be able to self-report may be at very high risk when three or more of these problems occur together:

- $\quad$ not seen a dentist for two or more years

- $\quad$ high-dependency care needs (e.g. requires assistance for activities of daily living, such as toileting, weak grip strength) and unable to physically brush their teeth

\section{Box 1 Maintaining oral care in older people according to risk}

\section{Healthy, robust patients}

Use fluoride toothpaste containing 1450 parts per million (most toothpastes), twice daily. Fluoride prevents decay and remineralises teeth. Fluoride binds calcium, forming fluorapatite which dissolves at a lower $\mathrm{pH}$.

Use a soft toothbrush. Brushing is very important to mechanically remove biofilm from teeth, gums, tongue and all denture surfaces.

Use an interproximal brush to clean between teeth.

To clean dentures, use mild soap, white vinegar (dilute 1:4 to remove calcific deposits) or cleanser. Leave dentures out at night to dry. Disinfect with commercial denture cleanser 1-2 times per week. Ensure denture cleanser is suitable for plastic or part metal dentures.

\section{High-risk patients}

Avoid mouthwashes or swabs containing alcohol, hydrogen peroxide, sodium bicarbonate, lemon and glycerin. Avoid confectionary with citric acid and sweet sticky foods. Discourage fruit juices, sugary drinks, caffeine, and frequency of snacking. Encourage eating of milk and cheese.

Ensure adequate hydration for saliva production - 2-2.5 $L$ fluid a day (minimum $1.6 \mathrm{~L} /$ day), frequently and after meals. Note that older people may have an altered urge to drink and may have difficulty swallowing.

Use pea size amounts of high-fluoride toothpaste (5000 parts per million), 1-2 times a day. This remineralises teeth and prevents or slows decay. Do not swallow. Spit but do not rinse so product stays on teeth.

Casein phosphopeptide amorphous calcium phosphate cream (available from dentists) remineralises teeth and is used as an adjunct after fluoride. Use 1-2 times a day. Add water to cream if mouth is dry. Leave a small amount on the teeth and do not rinse. Not suitable if the patient has a milk protein allergy, but can be used if lactose intolerant.

Use sugar-free gum 4-6 times a day after meals. Chewing neutralises mouth and plaque acids, aids in glucose clearance and maintains saliva gland function. Excessive consumption may have a laxative effect.

Frequently use artificial saliva and high $\mathrm{pH}$ oral lubricant (should not contain citric acid) on all oral tissues and under dentures for temporary symptomatic relief of dry mouth. Use a water-based moisturiser on lips.
Very high-risk patients (also use same products as with high-risk patients)

Non-staining chlorhexidine gluconate toothpaste $(0.05$ or $0.12 \%)$ at night can be used long term in older people and has prolonged, broad-spectrum antiseptic activity which reduces oral biofilm. Spit out but do not rinse. In some products increased concentrations of chlorhexidine gluconate can stain teeth (reversible), alter taste and increase calculus (tartar) formation. Use $0.5 \% \mathrm{gel}$ in localised areas or rinse with $0.2 \%$ short term for acute infections. As chlorhexidine is deactivated by fluoride in toothpastes, use high-fluoride toothpaste in the morning and chlorhexidine in the evening.

\section{Palliative care patients}

Apply water-based lip moisturiser (not petroleum-based). Use spray bottle applications for oral lubricants and alcohol and stain-free $2 \%$ chlorhexidine.

Clean teeth with low-strength sodium bicarbonate oral swabs, $2 \%$ chlorhexidine gluconate oral swabs (alcohol free), or both, to improve oral health and quality of life.

These interventions can be delivered by nurses or carers after meals and as needed. 
- cognitive impairment which interferes with their ability to brush their own teeth

- polypharmacy including medicines with anticholinergic effects

- $\quad$ a sublingual resting saliva $\mathrm{pH}^{*}$ below 5.8 (healthy pH 6.8-7.8, acidic 6-6.6, highly acidic $<5-5.8$ ), or difficulty wetting a disposable dental sponge micro-brush placed under the tongue for two seconds to wet $\mathrm{pH}$ paper outside the mouth. ${ }^{26}$

\section{Oral health in residential facilities}

Dentists tend to treat residents only for acute dental problems and not for routine preventive care. Frail older people who cannot maintain their own oral health require daily preventative care best delivered by nurses and carers trained in assisted brushing. This should be supported by regular professional cleanings and fluoride applications by oral therapists. Access to periodic assessments and regular oral care should be emphasised.

It would help if the person's dentist is included in the admission paperwork when they go into an aged-care facility. Currently there is no protocol to

* To test sublingual resting saliva, place a disposable dental sponge micro-brush under the tongue for two seconds. It is normal to be able to wet $\mathrm{pH}$ paper. If the $\mathrm{pH}$ paper cannot be made wet, it is likely the patient has salivary gland hypofunction or lacks adequate hydration at rest.

Full saliva testing of frail or fearful older people may not be practical. The benefits of saliva testing in this cohort have not been assessed in a randomised controlled trial. However, assessment of sublingual resting saliva $\mathrm{pH}$ offers a simple, quantitative and repeatable test of mouth acidity and quality of resting saliva, and can be performed in general practice and residential aged-care settings. ${ }^{26}$ notify dentists when their patients enter residential care. Some dental records, particularly dental implant specifications and oral health assessments, including dental X-rays, should be linked into medical records and transferred to the patient's residential aged-care facility. It is important for the dentist to communicate about treatment with the care team at the agedcare facility. For example, aggressive treatment of oral cancers may not be advisable for the very frail. Palliative care may be more appropriate involving only adequate analgesia and a tailored diet.

\section{Maintaining oral care}

Preventative oral products can help to reduce oral biofilm, remineralise teeth and improve saliva function and should be tailored to individual risk (Box 1). Many patients and carers often have difficulty understanding the use of multiple products so a simple handout for them is helpful with the appropriate products circled (Table). ${ }^{27}$

Using the resource links shown in Box 2, including the Oral Health Assessment Tool, raises the importance of oral health in a residential facility. There are practical training guides to help nursing staff gain the knowledge and confidence to assess residents and carry out preventive interventions. ${ }^{28}$

\section{Conclusion}

GPs are encouraged to look into the mouths of their patients to make oral health assessments and assess dental risk based on frailty and dependency in order to make early referrals to a dentist when required. Topical interventions are recommended based on risk and can prevent tooth decay. Polypharmacy is common in frail older people and some drugs can reduce saliva production. GPs should therefore prescribe drugs with the lowest anticholinergic affects to better maintain saliva function and oral health. $\varangle$

Conflicts of interest: none declared 


\section{Table Oral care product list}

\begin{tabular}{|c|c|c|c|}
\hline Purpose & Product & Brand & Comment \\
\hline \multirow{6}{*}{$\begin{array}{l}\text { Remineralise teeth } \\
\text { and prevent or slow } \\
\text { decay }\end{array}$} & \multirow{2}{*}{$\begin{array}{l}\text { High-fluoride } \\
\text { toothpaste ( } 5000 \\
\text { parts per million) }\end{array}$} & 3M Clinpro 5000 (3M) & Do not swallow, leave on teeth \\
\hline & & $\begin{array}{l}\text { Neutrafluor } 5000 \\
\text { (Colgate) }\end{array}$ & \\
\hline & \multirow{4}{*}{$\begin{array}{l}\text { Casein phosphopeptide } \\
\text { amorphous calcium } \\
\text { phosphate cream }\end{array}$} & \multirow[t]{4}{*}{ GC Tooth Mousse } & Available from dentists \\
\hline & & & Use 1-2 times a day \\
\hline & & & Leave on teeth \\
\hline & & & Adjunct after fluoride \\
\hline $\begin{array}{l}\text { Cleaning between } \\
\text { teeth }\end{array}$ & Interproximal brushes & $\begin{array}{l}\text { Ask pharmacist for } \\
\text { advice }\end{array}$ & \\
\hline \multirow{3}{*}{$\begin{array}{l}\text { Denture } \\
\text { maintenance }\end{array}$} & Liquid soap & \multirow{3}{*}{$\begin{array}{l}\text { Ask pharmacist for } \\
\text { advice }\end{array}$} & Brush all denture surfaces \\
\hline & Denture cleansers & & Disinfect and clean dentures \\
\hline & White vinegar & & Dissolves calcific deposits \\
\hline \multirow{3}{*}{$\begin{array}{l}\text { Stabilising poor- } \\
\text { fitting dentures that } \\
\text { cause ulcers and } \\
\text { sore spots }\end{array}$} & \multirow[t]{3}{*}{$\begin{array}{l}\text { Denture adhesive } \\
\text { cream/powder/strips }\end{array}$} & $\begin{array}{l}\text { Biotene Dry Mouth } \\
\text { Denture Grip }\end{array}$ & Reline or remake dentures \\
\hline & & Polident & \\
\hline & & $\begin{array}{l}\text { For other products ask } \\
\text { pharmacist }\end{array}$ & \\
\hline \multirow{5}{*}{$\begin{array}{l}\text { Temporary } \\
\text { palliative relief of } \\
\text { dry mouth }\end{array}$} & \multirow{5}{*}{$\begin{array}{l}\text { For artificial saliva, use } \\
\text { high } \mathrm{pH} \text { oral lubricant } \\
\text { without citric acid }\end{array}$} & \multirow[t]{5}{*}{$\begin{array}{l}\text { Ask pharmacist for } \\
\text { advice }\end{array}$} & $\begin{array}{l}\text { Delivered via oral spray, oral rinse, gel, } \\
\text { swabs or dissolving tablets }\end{array}$ \\
\hline & & & Before bed \\
\hline & & & Before eating \\
\hline & & & On and under dentures \\
\hline & & & As needed \\
\hline \multirow[t]{4}{*}{$\begin{array}{l}\text { Bleeding gums } \\
\text { (gingivitis) }\end{array}$} & \multirow{4}{*}{$\begin{array}{l}\text { Brush gums with } \\
\text { chlorhexidine } \\
\text { gluconate toothpaste }\end{array}$} & \multirow[t]{4}{*}{$\begin{array}{l}\text { Curasept } 0.05 \text { or } \\
0.12 \%\end{array}$} & $\begin{array}{l}\text { If unable to brush use non-staining, } \\
\text { alcohol-free products }\end{array}$ \\
\hline & & & Long-term use \\
\hline & & & $\begin{array}{l}\text { Do not use chlorhexidine with } \\
\text { toothpastes containing sodium lauryl } \\
\text { sulphate or fluoride }\end{array}$ \\
\hline & & & Refer to dentist \\
\hline \multirow[t]{2}{*}{ Hydration } & \multirow[t]{2}{*}{ Water } & & 2-2.5 L/day \\
\hline & & & Stop sweet, sticky, fruity drinks \\
\hline \multirow[t]{3}{*}{ Saliva function } & \multirow[t]{3}{*}{ Sugar-free gum } & & Improves saliva function \\
\hline & & & 4 times a day \\
\hline & & & Excessive use may cause diarrhoea \\
\hline \multirow{6}{*}{$\begin{array}{l}\text { Ulcers or denture } \\
\text { sore spots }\end{array}$} & Warm saline & & 3-4 times a day \\
\hline & \multirow{2}{*}{$\begin{array}{l}\text { Chlorhexidine } \\
\text { gluconate gel } 0.5 \%\end{array}$} & \multirow[t]{2}{*}{ Curasept ADS 350} & Short-term use \\
\hline & & & Localised topical area \\
\hline & \multirow{3}{*}{$\begin{array}{l}\text { Anti-inflammatory } \\
\text { mouth gel or paste }\end{array}$} & Difflam & \\
\hline & & Ora-Sed Jel & \\
\hline & & $\begin{array}{l}\text { Kenalog in Orabase } \\
\text { (steroid) }\end{array}$ & \\
\hline
\end{tabular}

Adapted from reference 27 


\section{Box 2 Resources to support oral health in older people}

\author{
Oral health care domain: Care of older people \\ toolkit \\ South Australian Dental Service \\ Contains links to: Staff portfolio, Professional portfolio, \\ Dental treatment pathway flow chart
}

\section{Oral Health Assessment Tool video}

South Australia Health

Oral health care for older people in NSW: carer support package

NSW Health

Instruction video on assisted brushing in

residential aged-care facilities

Dental Rescue, NSW
Instruction video on denture care

Dental Rescue, NSW

Anticholinergic Burden (ACB) Score Calculator

By Rebecca King and Steve Rabino

ACB calculator

Anticholinergic medicines and scores

Reducing ACB risk

The anticholinergic burden: therapeutic brief

Veterans' MATES, Department of Veterans' Affairs

\section{REFERENCES}

1. Desvarieux M, Demmer RT, Rundek T, Boden-Albala B, Jacobs DR Jr, Papapanou PN, et al.; Oral Infections and Vascular Disease Epidemiology Study (INVEST). Relationship between periodontal disease, tooth loss, and carotid artery plaque: the Oral Infections and Vascular Disease Epidemiology Study (INVEST). Stroke 2003;34:2120-5. https://doi.org/10.1161/01.STR.0000085086.50957.22

2. Holmlund A, Holm G, Lind L. Number of teeth as a predictor of cardiovascular mortality in a cohort of 7,674 subjects followed for 12 years. J Periodontol 2010;81:870-6. https://doi.org/10.1902/jop.2010.090680

3. Weijenberg RA, Scherder EJ, Lobbezoo F. Mastication for the mind--the relationship between mastication and cognition in ageing and dementia. Neurosci Biobehav Rev 2011;35:483-97. https://doi.org/10.1016/j.neubiorev.2010.06.002

4. Kim HY, Jang MS, Chung CP, Paik DI, Park YD, Patton LL, et al. Chewing function impacts oral health-related quality of life among institutionalized and community-dwelling Korean elders. Community Dent Oral Epidemiol 2009;37:468-76. https://doi.org/10.1111/j.1600-0528.2009.00489.x

5. Cerutti-Kopplin D, Feine J, Padilha DM, de Souza RF, Ahmadi M, Rompré $P$, et al. Tooth loss increases the risk of diminished cognitive function: a systematic review and meta-analysis. JDR Clin Trans Res 2016;1:10-9. https://doi.org/10.1177/2380084416633102

6. Stein PS, Desrosiers M, Donegan SJ, Yepes JF, Kryscio RJ. Tooth loss, dementia and neuropathology in the Nun study. J Am Dent Assoc 2007;138:1314-22. https://doi.org/10.14219/ jada.archive.2007.0046

7. Takeuchi K, Ohara T, Furuta M, Takeshita T, Shibata Y, Hata J, et al. Tooth loss and risk of dementia in the community: the Hisayama Study. J Am Geriatr Soc 2017;65:e95-100. https://doi.org/10.1111/jgs.14791

8. Dominy SS, Lynch C, Ermini F, Benedyk M, Marczyk A, Konradi A, et al. Porphyromonas gingivalis in Alzheimer's disease brains: evidence for disease causation and treatment with small-molecule inhibitors. Sci Adv 2019;5:eaau3333. https://doi.org/10.1126/sciadv.aau3333

9. Azarpazhooh A, Leake JL. Systematic review of the association between respiratory diseases and oral health J Periodontol 2006;77:1465-82. https://doi.org/10.1902/ jop.2006.060010

10. Yoneyama T, Yoshida M, Ohrui T, Mukaiyama $\mathrm{H}$, Okamoto $\mathrm{H}$, Hoshiba K, et al.; Oral Care Working Group. Oral care reduces pneumonia in older patients in nursing homes. J Am Geriatr Soc 2002;50:430-3. https://doi.org/10.1046/ j.1532-5415.2002.50106.x

11. Casanova L, Hughes FJ, Preshaw PM. Diabetes and periodontal disease: a two-way relationship. Br Dent J 2014;217:433-7. https://doi.org/10.1038/sj.bdj.2014.907
12. Wright FA, Law G, Chu SK, Cullen JS, Le Couteur DG. Residential age care and domiciliary oral health services: Reach-OHT-The development of a metropolitan oral health programme in Sydney, Australia. Gerodontology 2017;34:420-6. https://doi.org/10.1111/ger.12282

13. Silva $M$, Hopcraft $M$, Morgan $M$. Dental caries in Victorian nursing homes. Aust Dent J 2014;59:321-8. https://doi.org/ 10.1111/adj.12188

14. Deutsch A. An alternate technique of care using silver fluoride followed by stannous fluoride in the management of root caries in aged care. Spec Care Dentist 2016;36:85-92. https://doi.org/10.1111/scd.12153

15. Moffat AK, Apajee J, Pratt NL, Blacker N, Le Blanc VT, Roughead EE. Use of medicines associated with dry mouth and dental visits in an Australian cohort. Aust Dent $J$ 2020;65:189-95. https://doi.org/10.1111/adj.12750

16. Wolff A, Joshi RK, Ekström J, Aframian D, Pedersen AM, Proctor $\mathrm{G}$, et al. A guide to medications inducing salivary gland dysfunction, xerostomia, and subjective sialorrhea: a systematic review sponsored by the World Workshop on Oral Medicine VI. Drugs R D 2017;17:1-28. https://doi.org/ 10.1007/s40268-016-0153-9

17. Hilmer SN, Gnjidic D. Prescribing for frail older people Aust Prescr 2017:40:174-8. https://doi.org/10.18773/ austprescr.2017.055

18. Tan EC, Lexomboon D, Sandborgh-Englund G, Haasum Y, Johnell K. Medications that cause dry mouth as an adverse effect in older people: a systematic review and metaanalysis. J Am Geriatr Soc 2018;66:76-84. https://doi.org/10.1111/jgs.15151

19. Lertxundi U, Domingo-Echaburu S, Hernandez R, Peral J, Medrano J. Expert-based drug lists to measure anticholinergic burden: similar names, different results. Psychogeriatrics 2013;13:17-24. https://doi.org/10.1111/ j.1479-8301.2012.00418.x

20. Salahudeen MS, Duffull SB, Nishtala PS. Anticholinergic burden quantified by anticholinergic risk scales and adverse outcomes in older people: a systematic review. BMC Geriatr 2015;15:31. https://doi.org/10.1186/s12877-015-0029-9

21. Boustani M, Campbell N, Munger S, Maidment I, Foxet C. Impact of anticholinergics on the aging brain: a review and practical application. Aging Health 2008:4:311-20. https://doi.org/10.2217/1745509X.4.3.311

22. Liacos M, Page AT, Etherton-Beer C. Deprescribing in older people. Aust Prescr 2020;43:114-20. https://doi.org/10.18773/ austprescr.2020.033

23. Teoh L, Stewart K, Moses G. Where are oral and dental adverse drug effects in product information? Int J Pharm Pract 2020;28:591-8. https://doi.org/10.1111/ijpp.12650

24. Yuan A, Woo SB. Adverse drug events in the oral cavity. Oral Surg Oral Med Oral Pathol Oral Radiol 2015:119:35-47. https://doi.org/10.1016/j.0000.2014.09.009 
25. Slade GD. Oral health for older people: evaluation of the South Australian Dental Service Project. Populatiion Oral Health Series No. 6. Canberra: Australian Institute of Health and Welfare, and the Australian Research Centre for Population Oral Health; 2007. https://www.aihw.gov.au/ reports/dental-oral-health/oral-health-older-peoplesa-dental-service-project/contents/table-of-contents [cited $2021 \mathrm{Jul} 13$ ]

26. Walsh LJ. Clinical aspects of salivary biology for the dental clinician. Int Dent African Ed 2007;2:16-30.

http://www.moderndentistrymedia.com/jan_feb2012/ walsh.pdf [cited 2021 Jul 13]
27. South Australian Dental Service. Better oral health in residential care: professional portfolio: education and training program. SA Health; Adelaide; 2008. www.sahealth.sa.gov.au/wps/wcm/connect/ public+content/sa+health+internet/clinical+resources/ clinical+programs+and+practice+guidelines/older+people/ care+of+older+people+toolkit/oral+health+care+domain++care+of+older+people+toolkit [cited 2021 Jun 25]

28. Deutsch A, Siegel E, Cations M, Wright C, Naganathan V, Brodaty $\mathrm{H}$. A pilot study on the feasibility of training nurses to formulate multicomponent oral health interventions in a residential aged care facility. Gerodontology 2017;34:469-78. https://doi.org/10.1111/ger.12295

\section{FURTHER READING}

Australian Institute of Health and Welfare. Older Australia at a glance. AlHW: Canberra; 2018. https://doi.org/10.25816/

5 ec5bda5ed178 